\title{
Influence of Filler System on the Cure Characteristics and Mechanical Properties of Butyl Reclaimed Rubber
}

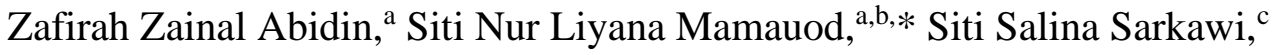
and Nurshamimi Shahirah Binti Saimi ${ }^{\text {a }}$

This research aimed to elucidate the effect of black and non-black filler systems on the cure characteristics and mechanical properties of butyl reclaimed rubber (BRR). In this study, BRR800 was the BRR investigated. Since reclaimed rubber is not entirely $100 \%$ rubber, actually being a mixture of rubber, carbon black, oil, zinc oxide, stearic acid and other compounding ingredients used in the original compounds, the reclaimed rubber content in each system was fixed at 161 parts per hundred (pphr). Each mixture was mixed using a two-roll mill. The fillers used in this study were carbon black and calcium carbonate. The Mooney viscosity, cure characteristics, crosslink density, and mechanical properties, such as hardness, abrasion resistance, compression set, tear strength, rebound resilience, and the tensile properties of the vulcanizates were investigated. The results showed that the Mooney viscosity of BRR800 filled with carbon black was increased effectively and had a faster curing time and higher crosslink density than BRR filled with calcium carbonate. In addition, except for compression set and elongation at break, the mechanical properties of BRR800 with a black filler system were higher than those of BRR800 with a non-black filler system.
\end{abstract}

Keywords: Butyl reclaimed rubber; Carbon black; Calcium carbonate; Cure characteristics; Mechanical properties

Contact information: a: Faculty of Applied Sciences, Universiti Teknologi MARA, 40450 Shah Alam, Selangor, Malaysia; b: Center of Polymer Composites Research and Technology, Institute of Science, Universiti Teknologi MARA, 40450 Shah Alam, Selangor, Malaysia; c: Technology and Engineering Division, Malaysian Rubber Board, RRIM Research Station, Sungai Buloh, 47000 Selangor, Malaysia;

* Corresponding author: nurliyana2219@uitm.edu.my

\section{INTRODUCTION}

Rubbers do not easily degrade or decompose hence producing large amounts of waste rubbers causes serious environmental and health issue (Movahed et al. 2016). Almost 10 million tons of rubber scraps are disposed of annually in the world, and discarded tires are a particularly large source of scrap tires. These discarded tires are a potential breeding site for mosquito larvae, which can lead to deadly diseases, such as dengue and malaria. In the past, these scraps were disposed of in the landfills, but recent technology development has allowed them to be recycled and reused to produce new rubber-based products. The goal of this is to build a sustainable economy; therefore a few waste management alternatives have been implemented to deal with the increasing amount of waste tires including tire-derived fuel, waste tire reuse/retreat, and reclamation of waste tire rubber, which is henceforth known as reclaimed rubber. Reclaimed rubber is obtained 
from vulcanized scrap rubber. Scrap rubber is different from scrap steel, as it requires special processing to be reused. After processing, the rubber obtained is called reclaimed rubber. Reclaimed rubber can come from flashing or from recycled rubber products, such as rubber tires and hoses, via grinding and subsequent treatment with alkali, oil, and plasticizer to soften them. Reclaimed rubber is a material obtained at essentially zero cost that can replace virgin rubber in many products and applications. Therefore, it is considered a rubber-compounding ingredient. However, a particular structure of vulcanized rubber makes reclaiming rubber more difficult than other materials, such as plastics. Reclaimed rubber is a mixture of rubber, carbon black, oil, zinc oxide, stearic acid, and other compounding ingredients used in the original compounds (Khalf et al. 2010; Ahmad et al. 2017; Basha et al. 2018). Reclamation of rubber waste materials has been an interest and priority in many industries, especially the automotive and transportation industries (Fukumori et al. 2002).

Reclaimed rubber has been widely researched. The incorporation of reclaimed rubber with virgin rubber is an alternative strategy to effectively utilize reclaimed rubber (Jacob et al. 2001). Blending of reclaimed rubber with other polymeric material is an excellent strategy to reuse rubber waste, as long as the components have good compatibility with one another (Hejna et al. 2020). Reclaimed rubber is combined with virgin rubber and fresh additives to obtain the properties necessary for certain products (Adhikari et al. 2000). This is done to improve the compatibility in the blends. For example, a study was conducted on the use of reclaimed rubber as reinforcement in styrene butadiene rubber (Debapriya and Debasish 2011). The reclaimed rubber in the study was used as an additive or filler to enhance the mechanical properties of styrene butadiene rubber. Tensile strength, elongation, tear resistance, and specific gravity increased with increased reclaimed rubber loading. The incorporation and dispersion of reclaimed rubber in virgin rubber affects product quality and allows economical cost production and competitiveness in the current market (De et al. 2013). In another study, a hot pressing method, which is a convenient and sustainable synthetic technology, was developed in order to reuse reclaimed tire rubber to produce gas-separation membranes. This is because rubber is a valuable material used for membrane preparation; hence reclaimed rubber was used (Tseng et al. 2019).

Butyl reclaimed rubber (BRR) is obtained by processing reclaimed butyl inner tubes. Butyl reclaimed rubber is known for its low buildup during processing and excellent curing properties. Before BRR is suitable for use, it must go through a modified digestion process to prevent the butyl rubber from contaminating the formulation and affecting the curing characteristics. Butyl reclaimed rubber has a shorter chain length than the original butyl rubber, so it is more easily processed than original butyl rubber due to the mastication process required during reclamation. In addition, the viscosity of BRR is lower than that of original rubber. Therefore, the calendaring, extruding, and mixing of compounds with BRR is faster and smoother ( $\mathrm{Li}$ and Kim 2012).

One of the compounding ingredients added to a rubber compound is filler. There are hundreds of filler types in the rubber industry, and they can be organic or inorganic (Ooi et al. 2013). Carbon black, clay, calcium carbonate, and calcium silicate are common examples of fillers added to rubber compounds. Usually, fillers are used to reinforce, improve, and modify rubber properties. When filler is added to rubber, it helps to increase the rubber modulus, abrasion, and tear resistance (Azrem et al. 2013). In this research, 
carbon black and calcium carbonate were used to study the effects of filler systems (black and non-black) on the properties of reclaimed rubber. In the rubber industry, carbon black plays an important role as a reinforcing filler. Carbon black is the most used filler because of its reduced particle size and huge range of available grades (Yuvaraj et al. 2018). Therefore, the mechanical properties of rubber are improved by the addition of carbon black. In addition, carbon black has a reinforcing effect due to the strong interactions between rubber and the surface of carbon black (Hoshikawa et al. 2016). Increases in carbon black lead to an increased reinforcing effect. Fillers are also added for economic reasons, such as reducing the cost of production (Vélez et al. 2016). Calcium carbonate is an inert filler that increases the volume and mass of products to reduce the cost of production. Inert fillers have only a small effect on the mechanical and dynamic mechanical properties of rubber products. Therefore, to obtain the required performance for rubber products, the appropriate amount of inert filler must be added to the rubber compound.

\section{EXPERIMENTAL}

\section{Materials}

The materials used in this study were butyl reclaimed rubber (BRR800), carbon black, calcium carbonate $\left(\mathrm{CaCO}_{3}\right)$, zinc oxide $(\mathrm{ZnO})$, stearic acid, benzothiazyl disulfide (MBTS), dipropylene glycol (DPG), tetramethylthiuram disulfide (TMTD), polymerized 2,2,4-trimethyl-1,1-dihydroquinoline (TMQ), and sulphur. The carbon black used was high abrasion furnace (HAF), N330 with a particle size of 28 to $36 \mathrm{~nm}$ and an average surface area of 76 to $80 \mathrm{~m}^{2} / \mathrm{g}$ while the calcium carbonate used was Hakuenka calcium carbonate with a particle size of $70 \mathrm{~nm}$ and an average surface area of $21 \mathrm{~m}^{2} / \mathrm{g}$. Butyl reclaimed rubber (BRR800) was supplied by Yong Fong Rubber Industries Sdn. Bhd. (Selangor, Malaysia), while the other ingredients were supplied by Malaysian Rubber Board (Selangor, Malaysia). According to Yong Fong Rubber Industries Sdn. Bhd., BRR800 is a higher grade of high quality BRR compared to BRR600, which is a common grade of BRR.

\section{Preparation of XNBR/BRR Blends}

The materials above were incorporated in an internal mixer and milled in a two-roll mill (Qingdao Shun Cheong Machinery Co., Ltd., Qingdao, China). In the case of mixing of BRR800 with calcium carbonate and other ingredients based on formulation shown in Table 1 in an internal mixer, a Bainite mixer of capacity 1.6 liters was used. The conditions of the mixing were a starting temperature of $80{ }^{\circ} \mathrm{C}$ and rotor speed of $110 \mathrm{RPM}$. The schedule of mixing was as follows:
0 minute - BRR800
0.5 minute - Zinc oxide, stearic acid, TMQ
1.0 minute - Calcium carbonate
2.5 minute - Sweep down feeding chute
3.0 minute - Dump 
The above masterbatch with various concerning curatives and additives such as sulphur, MBTS, DPG and TMTD was mixed on a $152 \times 30 \mathrm{~cm}$ two-roll mill running at low temperature. Similar conditions as above were used for the mixing of BRR800 with carbon black and other ingredients based on the formulation in Table 1, but a BR1600 Banbury mixer was used instead. The mixtures were then made into rubber compounds via placement in a mould and pressing between heated plates of an electrically heated hydraulic press (Qingdao Shun Cheong Machinery Co., Ltd., Qingdao China) at $150{ }^{\circ} \mathrm{C}$ for curing. The amounts of time for curing were fixed according to the results of curing characteristics, which are identified in Table 2. The amounts of chemicals used in the compounds are shown in Table 1.

Table 1. Compound Ingredients

\begin{tabular}{|c|c|c|}
\hline \multirow{2}{*}{ Ingredients } & \multicolumn{2}{|c|}{ Amount (pphr) } \\
\cline { 2 - 3 } & Compound 1 & Compound 2 \\
\hline BRR800 & 161 & 161 \\
\hline ZnO & 3 & 3 \\
\hline Calcium carbonate & 35 & 0 \\
\hline Carbon black & 0 & 35 \\
\hline Stearic acid & 0.2 & 0.2 \\
\hline MBTS & 1.25 & 1.25 \\
\hline DPG & 0.7 & 0.7 \\
\hline TMTD & 0.8 & 0.8 \\
\hline TMQ & 0.8 & 0.8 \\
\hline Sulphur & 1.3 & 1.3 \\
\hline
\end{tabular}

*pphr: part per hundred rubber

\section{Methods}

Testing and characterization

Mooney viscosity was determined according to ISO 289 (2017) via a Mooney viscometer Model MV2000 (Alpha Technologies, Hudson, OH, USA). The Mooney viscometer test was carried out using a large rotor at a rotation speed of $2 \mathrm{r} / \mathrm{min}$ and at a temperature of $100{ }^{\circ} \mathrm{C}$. Viscosity is a determinant of the mechanical processability of rubber. Mooney viscosity is defined as the shearing torque resisting rotation of a cylindrical metal disk (or rotor) embedded in rubber within a cylindrical cavity. Mooney viscosity is given in Mooney units $\left(\left(\mathrm{ML}(1+4) 100{ }^{\circ} \mathrm{C}\right)\right.$. For example, $50 \mathrm{ML}(1+4) 100{ }^{\circ} \mathrm{C}$ indicates that the measured viscosity was 50 Mooney units, ML indicates that a large standard rotor was used ( $\mathrm{L}$ is large and $\mathrm{S}$ is small), 1 is the preheating time (s) before the rotor starts to turn, and 4 is the running time (s) of actual rotor rotation before the final Mooney viscosity measurement is made at $100{ }^{\circ} \mathrm{C}$.

Each compound was vulcanized in a vulcanized press with a predetermined temperature and time. Results were obtained using a Monsanto Moving Die Rheometer (Qingdao Shun Cheong Machinery Co., Ltd., Qingdao, China) with approximately $4 \mathrm{~g}$ of each respective compound. Cure characteristics were studied at $150{ }^{\circ} \mathrm{C}$. 
Crosslink density test was studied in accordance to ASTM D6814 (2018) by immersing the rubber samples in toluene followed by immersion in acetone after a certain duration. Firstly, by using an electrical balance, cured samples of the compounds were weighed to $0.2 \mathrm{~g}$ to $0.25 \mathrm{~g}$, which was recorded as the initial weight. Each rubber sample was immersed in a closed bottle containing pure toluene $(10 \mathrm{~mL})$ at room temperature for $24 \mathrm{~h}$. The toluene was then replaced with a new portion of toluene, and the samples were allowed to swell for another $24 \mathrm{~h}$. After $24 \mathrm{~h}$, the swollen samples were weighed. Acetone was then added into the bottle for approximately $30 \mathrm{~min}$, and the samples were left to dry for $24 \mathrm{~h}$. The crosslink density was then determined by using the Flory-Rehner equation.

$$
\begin{aligned}
& M_{\mathrm{c}}=\left(-\rho_{\mathrm{r}} V_{\mathrm{s}} V_{\mathrm{r}}^{1 / 3}\right) /\left[\ln \left(1-V_{\mathrm{r}}\right)+V_{\mathrm{r}}+\varkappa V_{\mathrm{r}}^{2}\right] \\
& V_{\mathrm{r}}=1 /\left(1+Q_{\mathrm{m}}\right) \\
& V_{\mathrm{c}}=1 /\left(2 M_{\mathrm{c}}\right)
\end{aligned}
$$

In this set of equations, $\rho_{\mathrm{r}}$ is the rubber density, $V_{\mathrm{s}}$ is the molar volume of toluene, $V_{\mathrm{r}}$ is the volume fraction of the rubber in the swollen specimen, $Q_{\mathrm{m}}$ is the weight increase of the vulcanizate in toluene, $x$ is the interaction parameter of the rubber network-solvent, and $V_{\mathrm{c}}$ is the crosslink density in mol per cubic centimeter $\left(\mathrm{mol} / \mathrm{cm}^{3}\right)$.

Hardness testing was conducted in accordance with ASTM D2240 (2015) and determined via a Durometer (shore A) Qingdao Shun Cheong Machinery Co., Ltd., Qingdao, China). Hardness refers to a material's resistance to permanent indentation. The test specimen was disc shaped and had a thickness of $5 \mathrm{~mm}$. The hardness value, which was obtained at three different points on the test piece, was measured after approximately 15 s of contact with the Shore A indenter. The hardness test was performed to determine the suitability of the materials for a specific application.

As rubber comes into contact with various surfaces, wear characteristics are critical determinants of the ultimate performance of the end product. Abrasion testing can be used to predict the overall durability of the material in real-world applications. The Rotatory Drum Abrasion (DIN Abrasion) method measures volume loss due to the abrasive action of rubbing a test piece over a specified grade of abrasive sheet. The result can be reported as a relative volume loss or an abrasion resistance index (ARI).

The ability of rubber to return to its original thickness after prolonged compressive stress at a fixed temperature and deflection is measured via compression set testing. Compression set testing was conducted according to the method prescribed by ISO 815 (2008). In this procedure, stress was applied to the sample over a period of time to measure elasticity. A lower compression set percentage indicates that the material is better able to resist permanent deformation.

Crescent tear testing was used to measure tear resistance, which evaluates the force needed to create a tear in a material. The crescent tear test was conducted according to ISO 34 (2015), in which tear strength is defined as the force required to tear a test sample divided by specimen thickness. The specimen was placed in the grips of a universal testing machine (INSTRON; Norwood, Massachusetts, United States) in the tear strength mode and pulled at a rate of $20 \mathrm{in} / \mathrm{min}$ until rupture.

Tensile properties, such as tensile strength, elongation at break, and modulus, were measured. In this study, the tensile test used dumbbell-shaped test pieces, which were 
punched out from molded sheets, and the rubber specimens had gauge lengths of $20 \mathrm{~mm}$. The tensile test was performed according to ISO 37 (2017). Tensile testing was performed at a constant strain rate of $500 \mathrm{~mm} / \mathrm{min}$ until specimen fracture occurred.

\section{RESULTS AND DISCUSSION}

\section{Mooney Viscosity}

Mooney viscosity is used to characterize the processability of rubber. Mooney viscosity can be affected by filler choice and loading. Higher filler loading can increase the Mooney viscosity of rubber (Sae-Oui et al. 2017). Figure 1 shows that the incorporation of carbon black increased Mooney viscosity of the BRR800 more than calcium carbonate. With carbon black incorporated, BRR800 had a Mooney viscosity value of $67 \mathrm{MU}$. However, the Mooney viscosity value of BRR800 with calcium carbonate was $24 \mathrm{MU}$. This may have been due to the reinforcing effect of carbon black. Carbon black restricts chain mobility, hence increasing the viscosity (Ramarad et al. 2015). Moreover, the presence of carbon black in the BRR itself contributed to the fact that BRR generally has higher Mooney viscosity value than virgin rubber. The levels of filler-rubber interaction plays an important role in compound viscosity, which will influence the end properties of filled rubber (Du et al. 2019). Compound 1 imparted lower Mooney viscosity, which could be partly due to a lower degree of rubber-filler interaction compared to compound 2 . Fine fillers bind with a high percentage of rubber, whereas coarse fillers bind with almost none. Since calcium carbonate has a smaller surface area than carbon black, this results in low bonding between calcium carbonate and rubber.

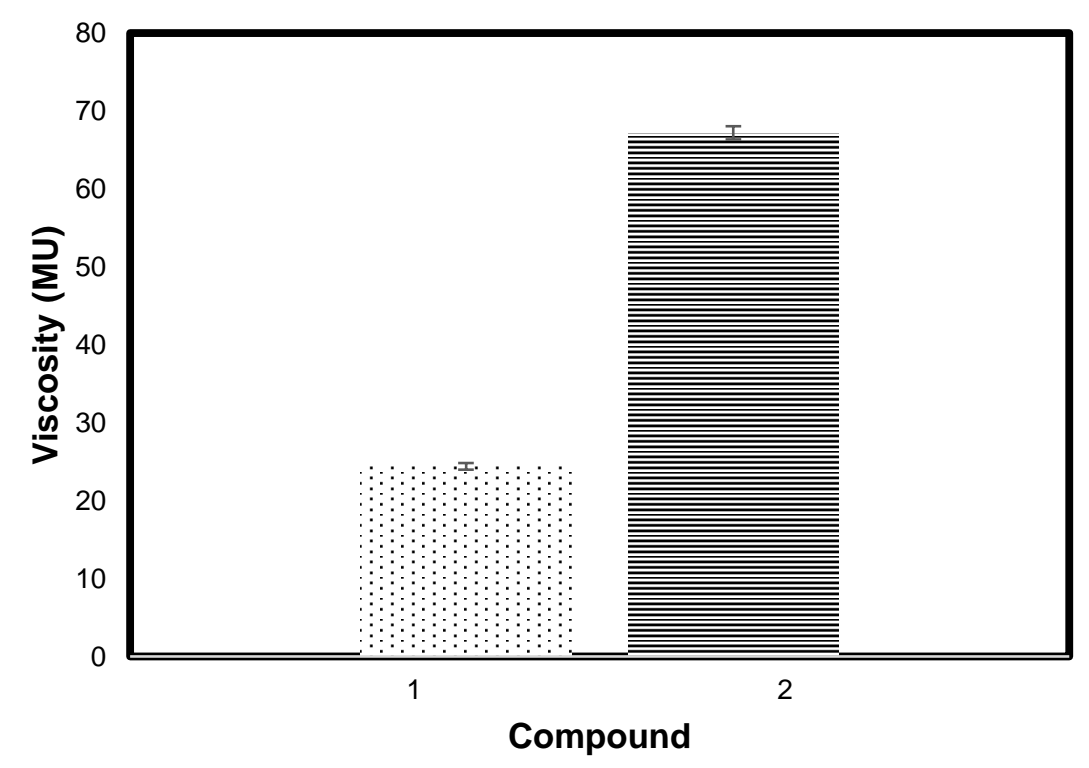

Fig. 1. The Mooney viscosity for compound 1 and compound 2 different filler systems 


\section{Cure Characteristics}

The cure rheographs of the compounds are shown in Fig. 2, while the corresponding cure characteristics such as the cure time $\left(T_{90}\right)$, scorch time $\left(T_{\mathrm{S} 2}\right)$, minimum torque $\left(M_{\mathrm{L}}\right)$, and maximum torque $\left(M_{\mathrm{H}}\right)$ are displayed in Table 2. The cure time of compound 2 was $3.4 \%$ lower than compound 1. A lower cure time would suggest enhancement in cure rate. This indicates that carbon black enhanced the cure time of compound 1. Curing properties of vulcanizates can be affected by the presence of hydroxyl or other oxygen-containing groups on the surface of carbon black. Compound 1 exhibits higher cure time than compound 2 because the nature of calcium carbonate particles being isotropic hence, a small nucleation effect. This could also be due to the interaction of the calcium carbonate in compound 1 with curatives, such as activator and accelerator. They tend to absorb more of the active ingredients. Consequently, the curative contents needed for the sulphur vulcanization process were decreased, which resulted in cure retardation. In addition, the existence of unreacted curative and precursors in the BRR may have contributed to the observed cure characteristics.

Considering the curing behaviour of compounds in Fig. 2, it can be seen that carbon black reduced the scorch time in compound 2. However, the use of calcium carbonate resulted in a longer scorch time for compound 1. Carbon black has a high surface area, which led to more heat buildup in compound 2 when it underwent the shearing process in the kneader. As carbon black was used in compound 2 and was present in the BRR itself, compound 2 was more viscous because the vulcanization reaction took place more readily (Junkong et al. 2015). This led to an increase in Mooney viscosity and a reduction in the scorch times of compound 2 . This result was also supported by the fact that compound 2 had a shorter cure time than compound 1 . The curing of compound 2 was faster and resulted in a stable network more quickly than that of compound 1 .

Compound 2 showed higher minimum and maximum torque values than compound 1. This result suggests that processing the compound became more difficult as the minimum and maximum torque values increased due to high stiffness, which was caused by the decreased polymer chain mobility. This supports increased value of $M_{\mathrm{H}}-M_{\mathrm{L}}$, which corresponded with the crosslink density of compound 2. In addition, the presence of precrosslinked BRR and other additives and curatives may have caused this result. It has been previously reported that the torque value of a rubber compound is affected by the crosslink density and chain entanglement of the compound itself (Sima and Akhbar 2016).

Table 2. Cure Characteristics of Compound 1 and Compound 2

\begin{tabular}{|c|c|c|}
\hline Data Points & Compound 1 & Compound 2 \\
\hline$M_{\mathrm{L}}(\mathrm{dNm})$ & 0.94 & 4.26 \\
\hline$M_{\mathrm{H}}(\mathrm{dNm})$ & 6.22 & 13.33 \\
\hline$M_{\mathrm{H}-}-M_{\mathrm{L}}(\mathrm{dNm})$ & 5.28 & 7.56 \\
\hline$T_{\mathrm{S} 2}(\mathrm{~min})$ & 8.38 & 3.82 \\
\hline$T_{90}(\mathrm{~min})$ & 24.67 & 23.84 \\
\hline$T_{95}(\mathrm{~min})$ & 27.2 & 26.71 \\
\hline
\end{tabular}




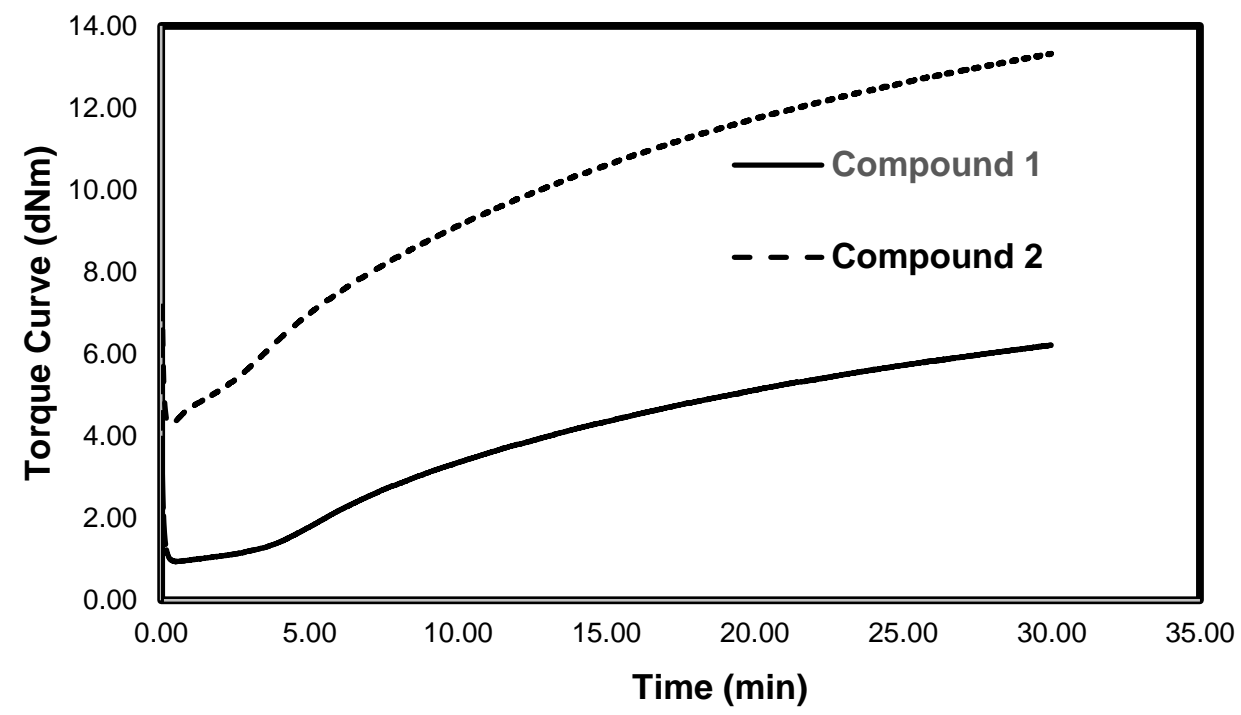

Fig. 2. The torque curves of compound 1 and compound 2

\section{Hardness and Crosslink Density}

Figures 3 and 4 show the influence of black and non-black filler systems on the hardness and crosslink density of BRR800. Compound 2 had a higher hardness value than compound 1. The high hardness value of compound 1 may have been due to its high crosslink density. Carbon black is an effective reinforcing filler that causes a reduction in the flexibility and elasticity of the rubber chain. Therefore, compound 1 was a more rigid rubber vulcanizate and harder than compound 2 .

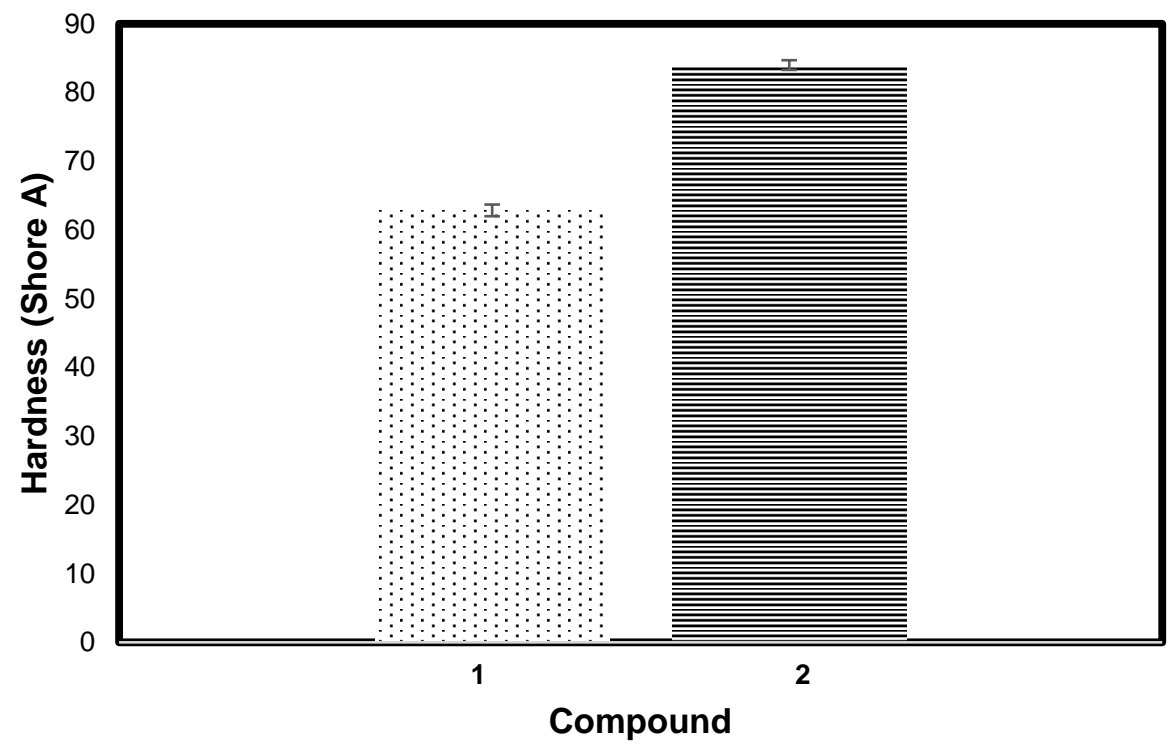

Fig. 3. The hardness testing results for compound 1 and compound 2 


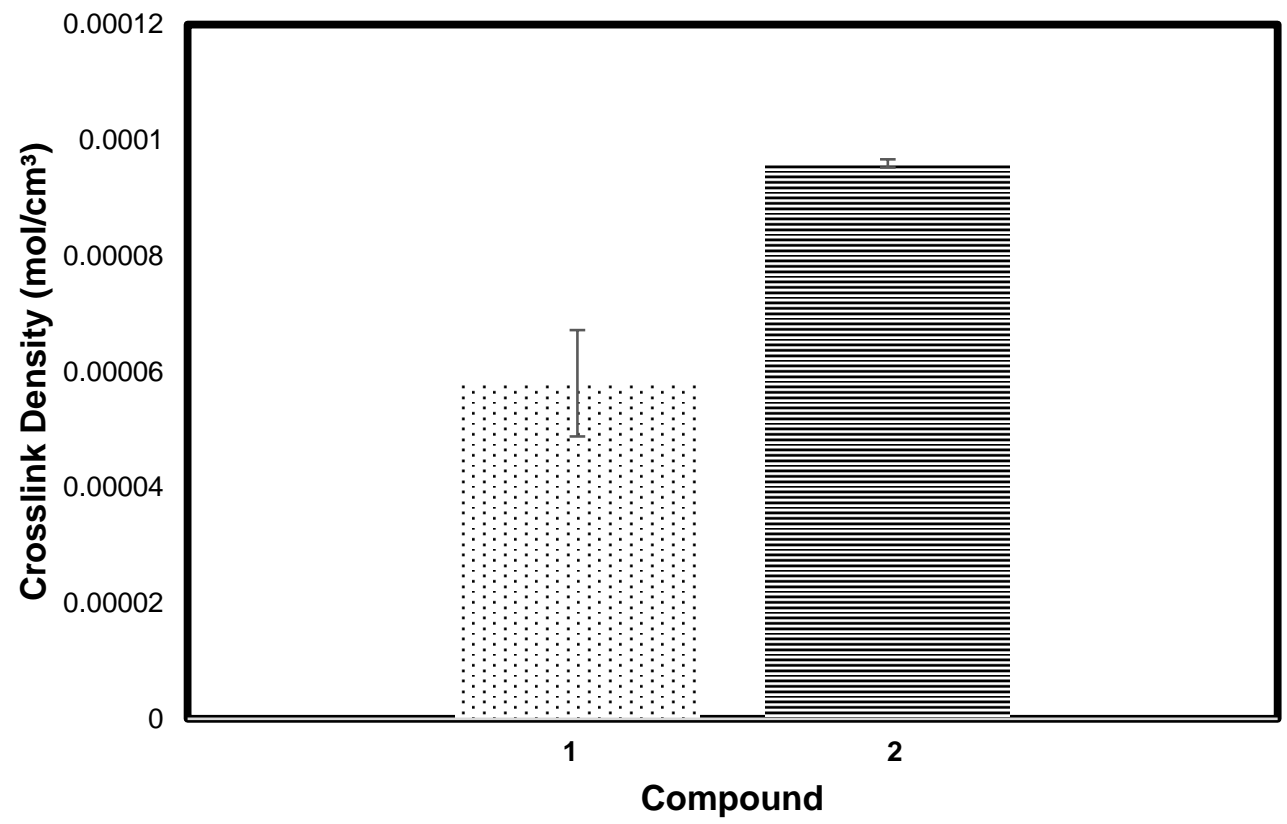

Fig. 4. The crosslink density results of compound 1 and compound 2

\section{Abrasion Resistance}

Figure 5 depicts the dependence of abrasion resistance on filler system type. Abrasion is a destructive phenomenon caused by wearing or friction (Han et al. 2015).

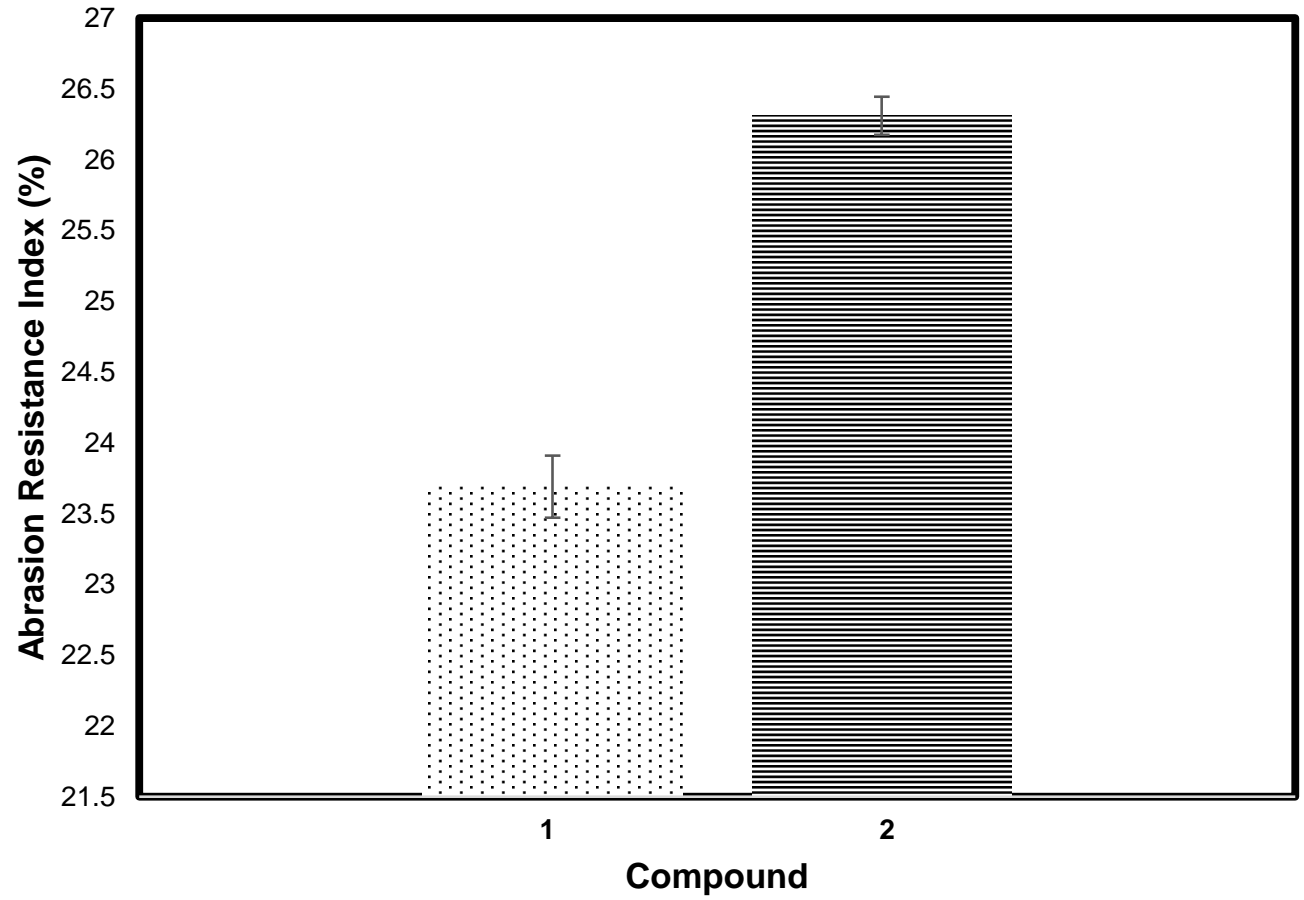

Fig. 5. The abrasion resistance results of compound 1 and compound 2 
As expected, compound 2, which was incorporated with carbon black, had a higher abrasion resistance than compound 1 , as values of $26.5 \%$ and $24 \%$ were observed for compound 2 and compound 1, respectively. Compound 2 had superior abrasion resistance to compound 1 due the higher crosslink density, as shown in Fig. 4, and carbon black, having a smaller particle size compared to calcium carbonate. Carbon black offers abrasion resistance to all rubbers. Since N330 has small particle size and a large external surface area, this helps to enhance rubber filler interaction. The smaller the particle size, the higher the resistance $f$ wear of a thread during a moderate service severity. It is noteworthy that excellent abrasion resistance can be obtained in BRR compounds by incorporating carbon black. Previous studies have reported that abrasion resistance is controlled by modulus, friction coefficient, and filler dispersion. High modulus, low friction coefficient, and good filler dispersion contribute to excellent abrasion resistance (Kato et al. 2012).

\section{Compression Set}

Compression set results are shown in Fig. 6. Compounds 1 and 2 exhibited dependence on filler system type, as the compression set value of compound $1(48 \%)$ was lower than that of compound 2 (60\%). Movahed et al. (2014) found that filler type affects the compression set of compounds. Compound 2, in which carbon black was incorporated, showed a larger increase in compression than compound 1. In addition, compound 2 had higher crosslink density than compound 1. The higher crosslinking between the rubber chains contributed to a reduction in chain mobility. This reduction prevented chain slippage when load was applied during compression set testing and resulted in lower permanent deformation of the rubber upon removal of the applied load. When chain mobility decreases, stiffness is induced in filled rubber compounds (Mostafa et al. 2009). As expected with high crosslink density, the probability of breaking the crosslink increased, which caused an increase in compression set percentage.

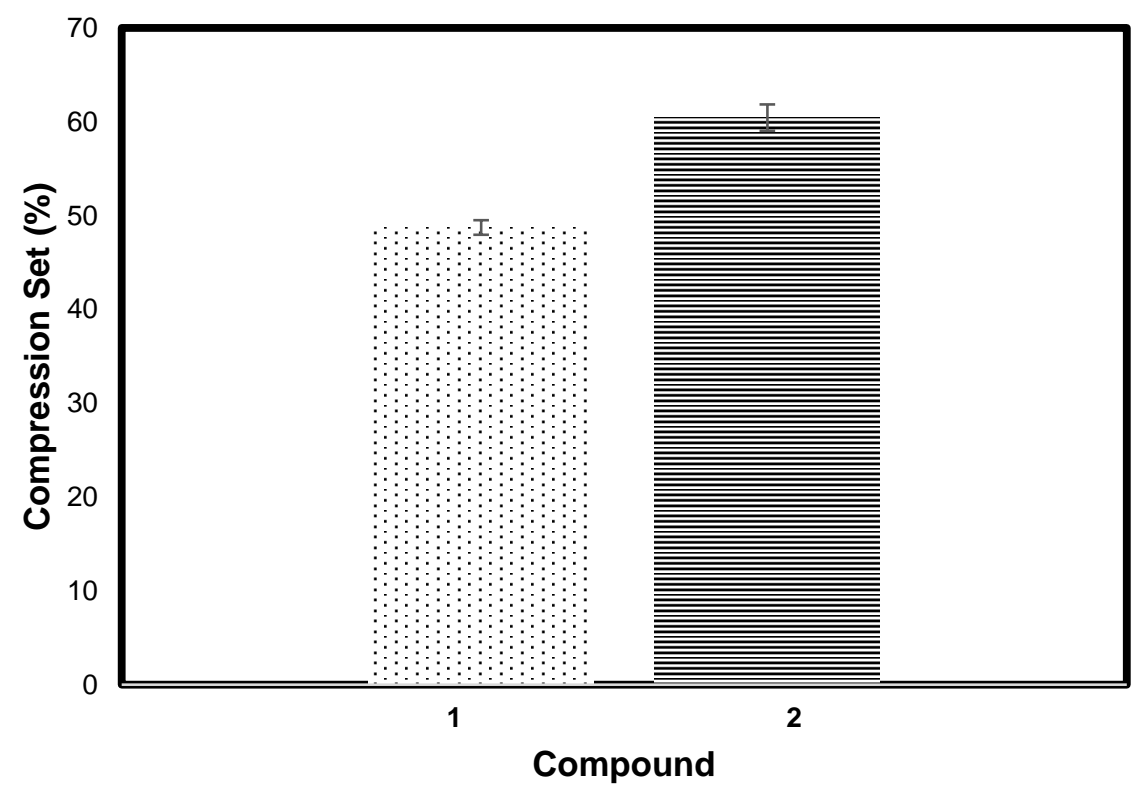

Fig. 6. The compression set results of compound 1 and compound 2 


\section{Tear Strength}

Figure 7 shows the tear strength results for compounds 1 and 2. Compound 1 had a lower tear strength than compound 2. Compound 1 had a tear strength value of $18 \mathrm{kN} / \mathrm{m}$, whereas the tear strength value of compound 2 was $28 \mathrm{kN} / \mathrm{m}$. The tear strength of compound 2 was attributed to the incorporation of carbon black as the reinforcing filler and the reinforcement from the presence of existing carbon black in BRR800.

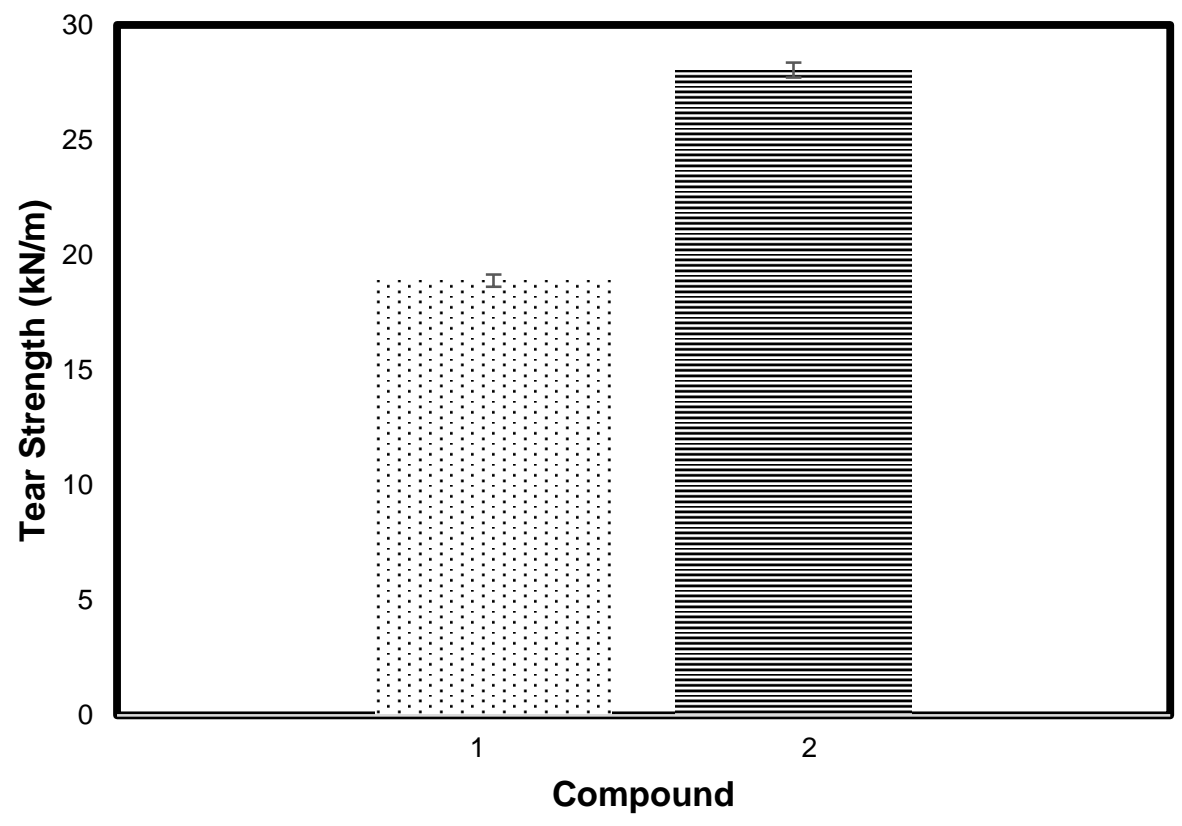

Fig. 7. The tear strength results of compound 1 and compound 2

\section{Tensile Properties}

Figures 8, 9, and 10 show the tensile properties of compounds 1 and 2. The results indicate that the added fillers of calcium carbonate and carbon black had an effect on the tensile strength, elongation at break, and modulus at 100\% elongation (M100) of the compounds. The tensile strength of compound 2 was $43 \%$ higher than that of compound 1 , as the values of tensile strength were $7 \mathrm{MPa}$ and 4.2 $\mathrm{MPa}$ for compound 2 and compound 1 , respectively. For elongation at break, compound 1 had a value of $431 \%$, and compound 2 had a value of $289 \%$. The black-filled system had a higher modulus than the non-blackfilled system, as compound 2, which was incorporated with carbon black, had a modulus of 3.7 MPa, and compound 1, which was incorporated with calcium carbonate, had a lower modulus value of $1.5 \mathrm{MPa}$. The mechanical properties of the rubber compound were expected to change greatly with the addition of carbon black, as carbon black enhances the mechanical properties of rubber by providing reinforcement (Ismail et al. 2013; Han et al. 2015). Further, the results suggest that the magnitude of rubber-filler interaction strongly affected tensile strength, elongation at break, and the modulus of both rubber compounds (Sae-Oui et al. 2017). The results indicate that the rubber had a relatively good rubberfiller interaction with carbon black, which was due to matching polarity. Carbon black is largely non-polar, while BRR800 is a non-polar rubber; hence, they both have excellent 
compatibility with one another, resulting in a good rubber-filler interaction. The particle size of carbon black also contributed to the results obtained because carbon black has a smaller particle size than calcium carbonate.

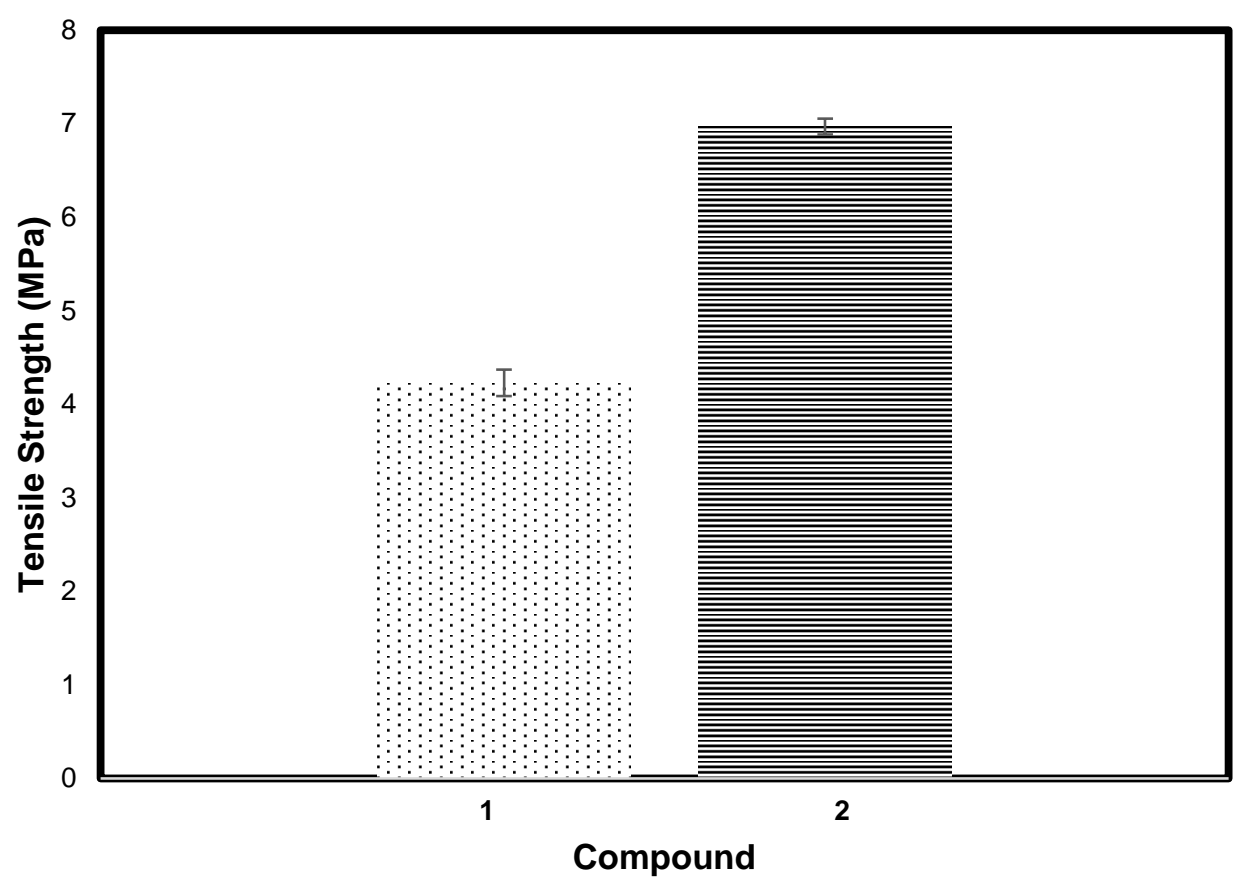

Fig. 8. The tensile strength results of compound 1 and compound 2

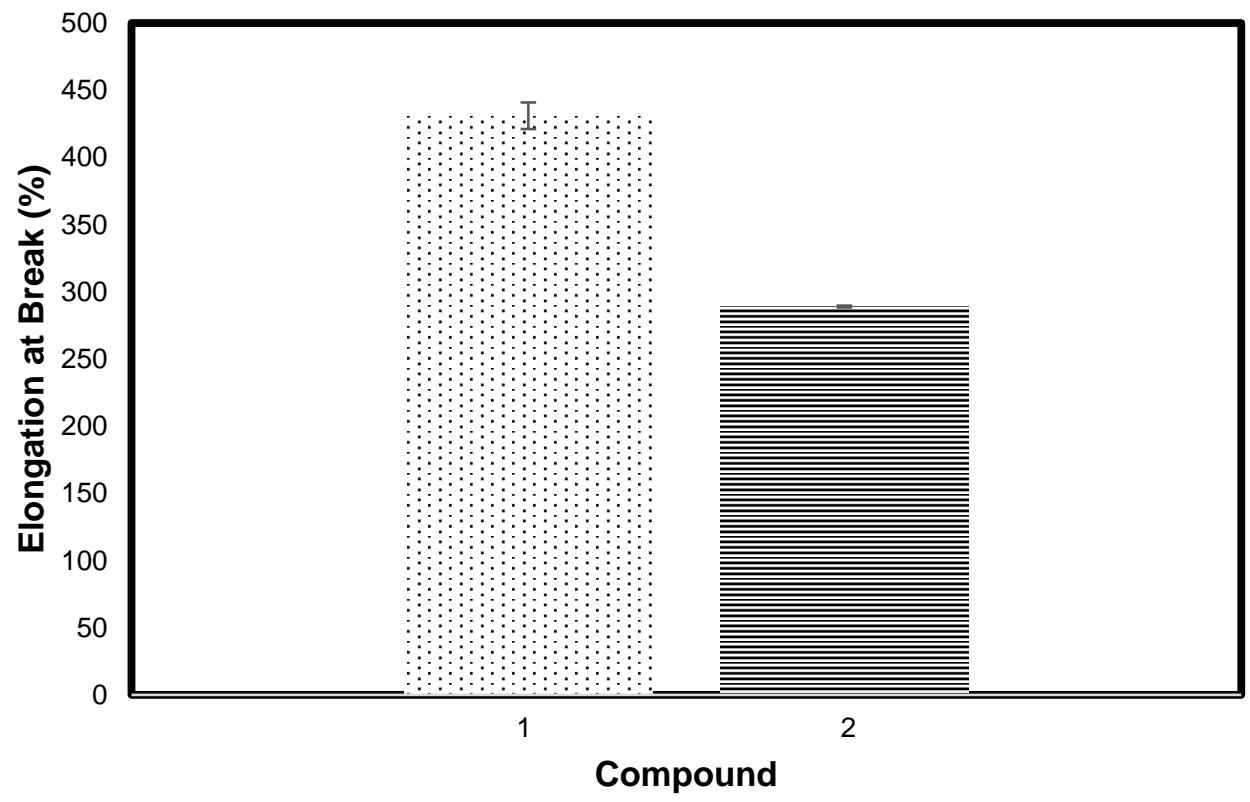

Fig. 9. The elongation at break results of compound 1 and compound 2 


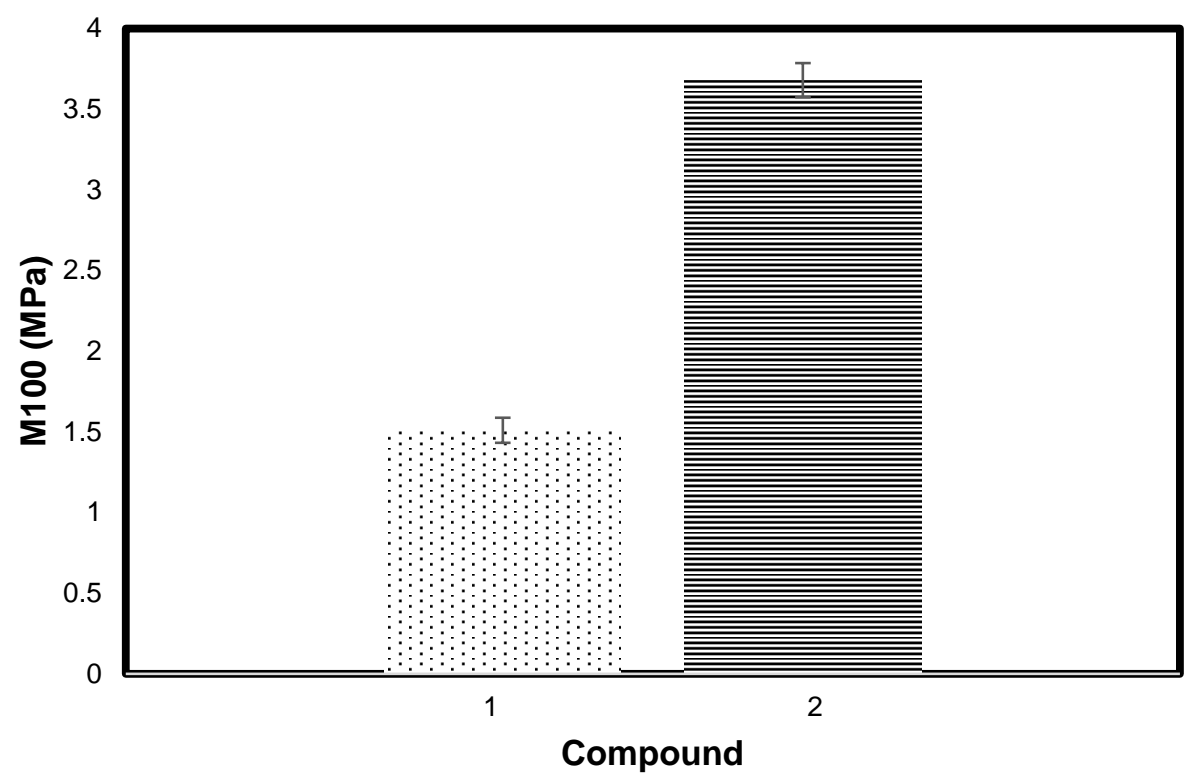

Fig. 10. The M100 results of compound 1 and compound 2

\section{CONCLUSIONS}

1. The use of a carbon black filler system resulted in a progressive increase in the Mooney viscosity of BRR, a shorter curing time, and higher crosslink density than the use of a non-black filler.

2. A combination of BRR800 with well-dispersed carbon black enhanced mechanical properties, such as hardness, abrasion resistance, tear strength, tensile strength, and modulus.

3. The compression set percentage was higher while the elongation at break was lower for BRR800 with a black filler system than for BRR800 with a non-black filler system. These results were due to the presence of carbon black as a reinforcing filler and the increased crosslink density in compound 2.

4. Compound incorporated with calcium carbonate showed lower value of hardness, abrasion resistance, tear strength and tensile strength compared to compound incorporated with carbon black. The fact that calcium carbonate is known as a semireinforcing filler while carbon black is one of reinforcing filler contributed to these results.

\section{ACKNOWLEDGEMENTS}

The authors thank the Malaysian Rubber Board for providing research facilities and technical assistance. In addition, the assistance of the Rubber Research Institute of the Malaysian Rubber Board staff with sample preparation and testing is much appreciated. 


\section{REFERENCES CITED}

Adhikari, B., De, D., and Maiti, S. (2000). "Reclamation and recycling of waste rubber," Progress in Polymer Science 25(7), 909-948. DOI: 10.1016/s0079-6700(00)00020-4

Ahmad, H. S., Ismail, H., and Rashid, A. A. (2017). "Hardness and swelling behaviour of epoxidized natural rubber/recycled acrylonitrile-butadiene rubber (ENR 50/NBRr) blends," AIP Conference Proceedings 1865(1), Article ID 040002. DOI: $10.1063 / 1.4993344$

ASTM D2240-05 (2010). "Standard test method for rubber property-Durometer hardness," American Society for Testing and Materials, West Conshohocken, United States.

ASTM D6814-02 (2018). "Standard test method for determination of percent devulcanization of crumb rubber based on crosslink density," American Society for Testing dan Materials, West Conshohocken, United States.

Azrem, A. A., Noriman, N., and Razif, M. (2013). "The effects of carbon black and calcium carbonate as a filler on cure characteristic and physical properties of SBR/CRR blends," Key Engineering Materials 594-595, 867-871. DOI: 10.4028/www.scientific.net/kem.594-595.867

Basha, S. K. T., Divya, R., Menon, A. U., Ashok, N., and Balachandran, M. (2018). "Cure and degradation kinetics of sulfur cured nanocomposites of EPDM-NBR rubber blends," Materials Today: Proceedings 5(11), 23586-23595. DOI: 10.1016/j.matpr.2018.10.147

De, D., Panda, P. K., Roy, M., and Bhunia, S. (2013). "Reinforcing effect of reclaim rubber on natural rubber/polybutadiene rubber blends," Materials \& Design 46, 142 150. DOI: $10.1016 /$ j.matdes.2012.10.014

Debapriya, D., and Debasish, D. (2011). "Processing and material characterization of a reclaimed ground rubber tire reinforced styrene butadiene rubber," Materials Sciences and Applications 2, 486-496. DOI: 10.4236/msa.2011.25066

Du, X., Zhang, Y., Pan, X., Meng, F., You, J., and Wang, Z. (2019). “Preparation and properties of modified porous starch/carbon black/natural rubber composites," Composites Part B: Engineering 156, 1-7. DOI: 10.1016/j.compositesb.2018.08.033

Fukumori, K., Matsushita, M., Okamoto, H., Sato, N., Suzuki, Y., and Takeuchi, K. (2002). "Recycling technology of tire rubber," JSAE Review 23(2), 259-264. DOI: 10.1016/s0389-4304(02)00173-x

Han, J., Zhang, Y., Wu, C., Xie, L., and Ma, Y. (2015). "Wet sliding abrasion of natural rubber composites filled with carbon black at different applied loads," Journal of Macromolecular Science Part B 54(4), 401-410. DOI: 10.1080/00222348.2015.1012477

Hejna, A., Zedler, Ł., Przybysz-Romatowska, M., Cañavate, J., Colom, X., and Formela, K. (2020). "Reclaimed rubber/poly( $\varepsilon$-caprolactone) blends: Structure, mechanical, and thermal properties," Polymers 12(5), 1204. DOI: 10.3390/polym12051204

Hoshikawa, Y., An, B., Kashihara, S., Ishii, T., Ando, M., Fujisawa, S., Koutarou, H., Hamatani, S., Yamada, H., and Kyotani, T. (2016). "Analysis of the interaction between rubber polymer and carbon black surfaces by efficient removal of 
physisorbed polymer from carbon-rubber composites," Carbon 99, 148-156. DOI: 10.1016/j.carbon.2015.12.003

Ismail, H., Noimam, N. Z., Woon, H. W., and Ridhwan, J. N. M. (2013). "The effects of carbon black, silica and calcium carbonate in virgin pe/recycle PE/EPDM blends: Thermal properties \& swelling analysis," Advanced Materials Research 795, 372376. DOI: $10.4028 / w w w . s c i e n t i f i c . n e t / a m r .795 .372$

ISO 289-2 (2017). "Rubber, unvulcanized-determination using a shearing-disc viscometer-part 4: Determination of pre-vulcanization characteristics," International Organization for Standardization, Tokyo, Japan.

ISO 815-2 (2014). "Rubber, vulcanized or thermoplastic-determination of compression set - Part 2: At low temperature," International Organization for Standardization, Geneva, Switzerland.

ISO 34-1 (2015). "Rubber, vulcanized or thermoplastic - Determination of tear strength Part 1: Trouser, angle and crescent test pieces," International Organization for Standardization, Tokyo, Japan.

ISO 37 (2017). "Rubber, vulcanized or thermoplastic- determination of tensile stress strain properties," International Organization for Standardization, Tokyo, Japan.

Jacob, C., De, P. P., Bhowmick, A. K., and De, S. K. (2001). "Recycling of EPDM waste. II. Replacement of virgin rubber by ground EPDM vulcanizate in EPDM/PP thermoplastic elastomeric composition," Journal of Applied Polymer Science 82(13), 3304-3312. DOI: 10.1002/app.2189

Junkong, P., Kueseng, P., Wirasate, S., Huynh, C., and Rattanasom, N. (2015). "Cut growth and abrasion behaviour, and morphology of natural rubber filled with MWCNT and MWCNT/carbon black," Polymer Testing 41, 172-183. DOI: 10.1016/j.polymertesting.2014.11.009

Kato, A., Ikeda, Y., and Kohjiya, S. (2012). "Carbon black-filled natural rubber composites: Physical chemistry and reinforcing mechanism," in: Polymer Composites, S. Thomas, J. Kuruvilla, S. K. Malhotra, K. Goda, and M. S. Sreekala (eds.), Wiley-CVH Verlag GmbH \& Co. KGaA, Weinheim, Germany, pp. 515-543.

Khalf, A. I., Nashar, D. E. E., and Maziad, N. A. (2010). "Effect of grafting cellulose acetate and methylmethacrylate as compatibilizer onto NBR/SBR blends," Materials \& Design 31(5), 2592-2598. DOI: 10.1016/j.matdes.2009.11.027

Li, L., and Kim, J. K. (2012). "Mechanical properties of recycled butyl rubber/virgin butyl rubber composite," Advanced Materials Research 621, 8-10. DOI: 10.4028/www.scientific.net/amr.621.8

Mostafa, A., Abouel-Kasem, A., Bayoumi, M., and El-Sebaie, M. (2009). "Effect of carbon black loading on the swelling and compression set behavior of SBR and NBR rubber compounds," Materials \& Design 30(5), 1561-1568. DOI: 10.1016/j.matdes.2008.07.043

Movahed, S. O., Ansarifar, A., and Mirzaie, F. (2014). "Effect of various efficient vulcanization cure systems on the compression set of a nitrile rubber filled with different fillers," Journal of Applied Polymer Science 132(8), Article ID 41512. DOI: 10.1002/app.41512 
Movahed, S. O., Ansarifar, A., and Estagy, S. (2016). "Review of the reclaiming of rubber waste and recent work on the recycling of ethylene-propylene-diene rubber waste," Rubber Chemistry and Technology 89(1), 54-78. DOI: 10.5254/rct.15.84850

Ooi, Z. X., Ismail, H., and Bakar, A. A. (2013). "Optimisation of oil palm ash as reinforcement in natural rubber vulcanisation: A comparison between silica and carbon black fillers," Polymer Testing 32(4), 625-630. DOI:

10.1016/j.polymertesting.2013.02.007

Ramarad, S., Khalid, M., Ratnam, C. T., Chuah, A. L., and Rashmi, W. (2015). "Waste tire rubber in polymer blends: A review on the evolution, properties and future," Progress in Materials Science 72, 100-140. DOI: 10.1016/j.pmatsci.2015.02.004

Sae-Oui, P., Suchiva, K., Sirisinha, C., Intiya, W., Yodjun, P., and Thepsuwan, U. (2017). "Effects of blend ratio and SBR type on properties of carbon black-filled and silica-filled SBR/BR tire tread compounds," Advances in Materials Science and Engineering 2017, Article ID 2476101. DOI: 10.1155/2017/2476101

Sima, R., and Akhbar, S. (2016). "Vulcanization kinetics and reversion behavior of natural rubber/styrene-butadiene rubber blend filled with nanodiamond-the role of sulfur curing system," European Polymer Journal 81, 98-113. DOI:

10.1016/j.eurpolymj.2016.05.021

Tseng, H.-H., Lin, Z.-Y., Chen, S.-H., Lai, W.-H., and Wey, M.-Y. (2019). "Reuse of reclaimed tire rubber for gas-separation membranes prepared by hot-pressing," Journal of Cleaner Production 237, 117739. DOI: 10.1016/j.jclepro.2019.117739

Vélez, J. S., Velásquez, S., and Giraldo, D. (2016). "Mechanical and rheometric properties of gilsonite/carbon black/natural rubber compounds cured using conventional and efficient vulcanization systems," Polymer Testing 56, 1-9. DOI: 10.1016/j.polymertesting.2016.09.005

Yuvaraj, P., Rao, J. R., Fathima, N. N., Natchimuthu, N., and Mohan, R. (2018). "Complete replacement of carbon black filler in rubber sole with $\mathrm{CaO}$ embedded activated carbon derived from tannery solid waste," Journal of Cleaner Production 170, 446-450. DOI: 10.1016/j.jclepro.2017.09.188

Article submitted: March 15, 2020; Peer review completed: June 4, 2020; Revised version received and accepted: June 14, 2020; Published: June 17, 2020.

DOI: 10.15376/biores. 15.3.6045-6060 